\title{
Structural Characterization of Emeraldine-Salt Polyaniline/Gold Nanoparticles Complexes
}

\author{
E. A. Sanches, ${ }^{1}$ J. C. Soares, ${ }^{1}$ R. M. Iost, ${ }^{2}$ V. S. Marangoni, ${ }^{2}$ G. Trovati, ${ }^{2}$ T. Batista, ${ }^{2}$ \\ A. C. Mafud, ${ }^{1}$ V. Zucolotto, ${ }^{1}$ and Y. P. Mascarenhas ${ }^{1}$ \\ ${ }^{1}$ Institute of Physics of São Carlos (IFSC), University of São Paulo (USP), P.O. Box 369, 13560-970 São Carlos, SP, Brazil \\ ${ }^{2}$ Institute of Chemistry of São Carlos (IQSC), University of São Paulo (USP), P.O. Box 780, 13560-970 São Carlos, SP, Brazil
}

Correspondence should be addressed to E. A. Sanches, edgar.sanches@ifsc.usp.br

Received 21 July 2011; Accepted 29 September 2011

Academic Editor: Chunyi Zhi

Copyright () 2011 E. A. Sanches et al. This is an open access article distributed under the Creative Commons Attribution License, which permits unrestricted use, distribution, and reproduction in any medium, provided the original work is properly cited.

Gold nanoparticles (Au NPs) stabilized with polyamidoamine dendrimers (Au-PAMAM) or sodium citrate (Au-CITRATE) were synthesized and complexed with polyaniline emeraldine-salt form (ES-PANI). The complexes were characterized using structural and morphological techniques, including X-Ray Diffraction (XRD), Scanning Electron Microscopy (SEM), Zeta Potential analyses, and Fourier-Transformed Infrared spectroscopy (FTIR). When the Au-CITRATE NPs are added to the polymeric solution, the formation of a precipitate is clearly observed. The precipitate exhibited a different morphology from that found for ES-PANI and Au-CITRATE NPs, suggesting the formation of ES-PANI coating over the surface of Au-CITRATE NPs. On the other hand, when the Au-PAMAM NPs are incorporated into the ES-PANI solution, none interaction was observed, probably due to the repulsive electrostatic interactions, being the organization of the ES-PANI chains unaffected by the presence of the Au-PAMAM NPs.

\section{Introduction}

The discovery and development of new semiconducting polymers have brought a number of technological applications. In general, the ability to combine the electrical properties of semiconductors with the versatility and processability of polymers is the basic concept behind the development of intrinsically conducting polymers (ICPs) [1-5]. Polyaniline (PANI) is one of the most important conducting polymer due to its easy preparation and doping process and environmental stability [6]. The fully reduced leucoemeraldine-base form (LB-PANI, $y=1$ ) and the fully oxidized pernigraniline-base form (PB-PANI, $y=0$ ) are nonconducting forms of PANI. The partially oxidized emeraldine-base (EB-PANI, $y=0.5$ ) is a semiconductor, which becomes the conducting emeraldine-salt form (ES-PANI) after protonation [6-8].

Conducting polymer/inorganic nanoparticle composites has attracted attention due to their great potential for applications [9-15] such as nanoelectronics [16], gas sensors [17, 18], biosensors [19-21], capacitors [22], and catalysts [23]. Among the inorganic nanomaterials, gold nanoparticles have received great attention because of their unique electrical and optical properties, as well as their extensive applications in biomedical areas [24]. Composites containing organic polymers and inorganic nanoparticles provide a completely new class of materials with novel properties [25-29].

In this study, there was made a structural characterization of hybrid complexes based upon Au NPs and ES-PANI. Two different Au NPs had been used, stabilized with polyamidoamine dendrimers (Au-PAMAM) or sodium citrate (AuCITRATE). We aimed at investigating the interactions between Au NPs and ES-PANI in solution and their correlation with complex stability.

\section{Experimental}

2.1. Synthesis of Au NPs. Au NPs were chemically synthesized using two stabilizers, namely, polyamidoamine dendrimer PAMAM - generation 4, or sodium citrate in order to obtain positively and negatively charged nanoparticles. Au-PAMAM nanohybrids were prepared using $5 \mathrm{~mL}$ of $\mathrm{KAuCl}_{4}$ solution $\left(1 \mathrm{mmol} \cdot \mathrm{L}^{-1}\right)$ added to $5 \mathrm{~mL}$ of PAMAM $\left(0.07 \mathrm{mmol} \cdot \mathrm{L}^{-1}\right)$ and $5 \mathrm{~mL}$ of formic acid $\left(1 \mathrm{mmol} \cdot \mathrm{L}^{-1}\right)$ [30]. Au-CITRATE 


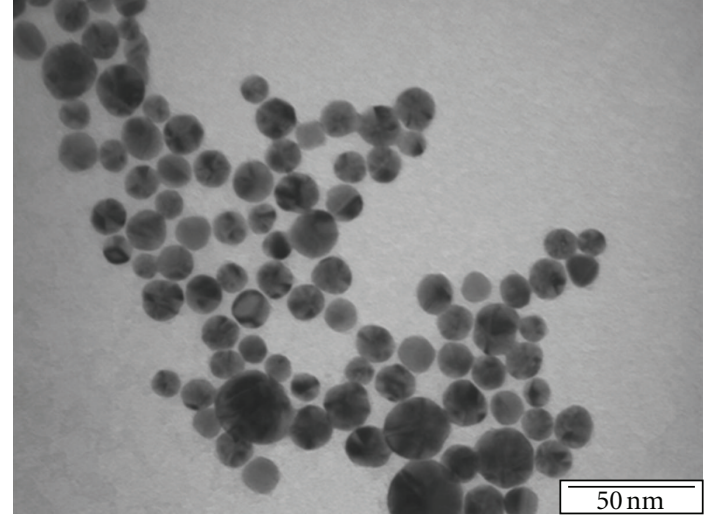

(a)

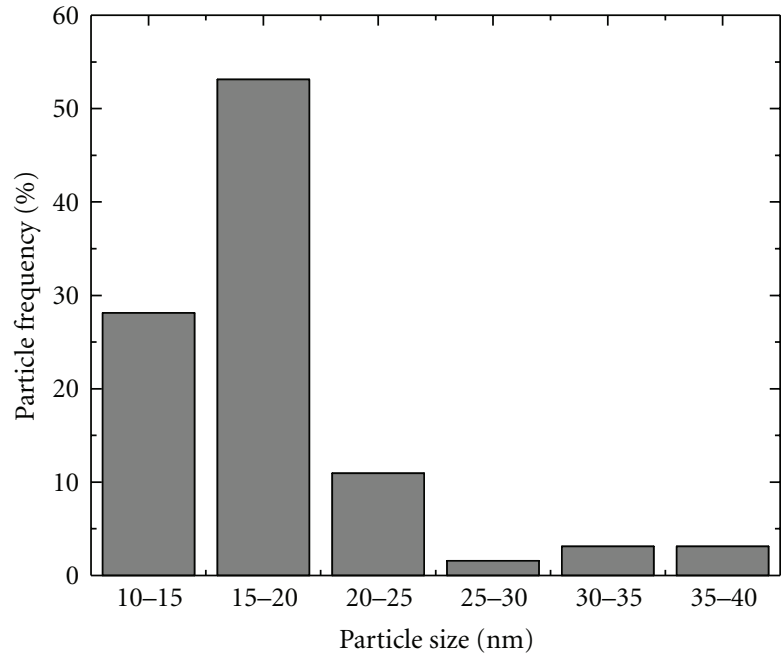

(b)

Figure 1: (a) TEM images of the Au-PAMAM NPs and (b) Histogram of the Au size distribution.

nanoparticles were prepared using $5 \mathrm{~mL}$ of $\mathrm{HAuCl}_{4}\left(2 \mathrm{~g} \cdot \mathrm{L}^{-1}\right)$ dissolved in $40 \mathrm{~mL}$ of water and $100 \mathrm{mg}$ of sodium citrate (salt form) dissolved in $5 \mathrm{~mL}$ of water [31]. Addition of the sodium citrate solution to the gold solution was followed by increasing the temperature to $95^{\circ} \mathrm{C}$ and continuous stirring for $1 \mathrm{~h}$. A clear red solution was formed during the addition of sodium citrate solution. The final Au NPs solutions were kept in the dark during $4 \mathrm{~h}$ before using.

\subsection{Synthesis of Emeraldine-Salt Polyaniline (ES-PANI) and} Samples Characterization. Aniline (Aldrich) was used after distillation. $\mathrm{HCl}(a q)$, acetone, and $\left(\mathrm{NH}_{4}\right)_{2} \mathrm{~S}_{2} \mathrm{O}_{8}$ were commercially obtained (Aldrich) and used without further purification. Synthesis of ES-PANI was performed based on the method described by Bhadra et al. [32] with some modifications. Distilled aniline $(0.2 \mathrm{M})$ was dissolved in $500 \mathrm{~mL}$ of $\mathrm{HCl}(1.0 \mathrm{M})$ at room temperature. A stoichiometric calculated amount of ammonium persulfate $(11.5 \mathrm{~g})$ was dissolved in $200 \mathrm{~mL}$ of $\mathrm{HCl}(1.0 \mathrm{M})$, placed in a burette, and added drop by drop to the above solution for $2 \mathrm{~h}$. The system was kept under constant stirring for $3 \mathrm{~h}$. The dark green precipitate resulting from this reaction $(20 \mathrm{mg})$ was solubilized in $10 \mathrm{~mL}$ of distilled water, sonificated for $0.5 \mathrm{~h}$, and filtered. The resulting solution was separated in aliquots of $1.5 \mathrm{~mL}$, in which were added volumes of 50, 100, and $500 \mathrm{~mL}$ of Au-PAMAM NPs. The same procedure was repeated for the additions of Au-CITRATE NPs.

Transmission Electron Microscopy (TEM) images for Au-PAMAM and Au-CITRATE NPs solutions were obtained on a Philips CM120 electron microscope operating at an acceleration voltage of $120 \mathrm{kV}$. Samples were ultrasonically dispersed for $1 \mathrm{~h}$ and then a drop of each one suspension was placed in a carbon-coated copper grid, which was left to stand for $24 \mathrm{~h}$. Scanning Electron Microscopy (SEM) images were obtained using a Supra 35, Carl Zeiss, $3.0 \mathrm{kV}$. Powder samples were deposited on a carbon tape and the surface morphology was obtained at room temperature.
Charges of the ES-PANI/Au NPs solutions were measured using a Zetasizer Nano ZS (Malvern) and a Titrator MPT2. XRD patterns were collected with a Rigaku RotaFlex equipped with a graphite monochromator, operating with $\mathrm{CuK} \alpha$ radiation, $50 \mathrm{kV}$, and $100 \mathrm{~mA}$. The data collection was recorded in the range of $2 \theta=5-70^{\circ}$ with a step of $0.02^{\circ}$ and 2 seconds/step. Fourier-Transformed Infrared spectroscopy (FTIR) was performed in the transmission mode on a Nexus 470 FTIR spectrometer. The spectra were obtained over 32 scans.

\section{Results}

Figure 1(a) shows the TEM images of the Au-PAMAM NPs. It is possible to observe that the particles are distributed in a spherical shape. The corresponding histogram (Figure 1(b)) indicates a broad distribution ranging from 10 to $40 \mathrm{~nm}$. The largest percentage corresponds to particles between 15 and $20 \mathrm{~nm}$, representing 53\%. Figure 2(a) shows the TEM images of the Au-CITRATE NPs. The corresponding histogram (Figure 2(b)) indicates a small nanoparticles sizes variation, showing that they are distributed, in similar percentage (50\%) between 10 and $20 \mathrm{~nm}$.

The as-synthesized ES-PANI powder (Figure 3) seems to have nanofibers morphology and showed a branched geometry. Figure 4 shows the Au-PAMAM NPs dispersed on the polymer chains, suggesting that the Au-PAMAM NPs, as expected, did not interact with the ES-PANI, preserving its chain conformation. Further, as shown in Figure 5, the composite formed by the interaction between ES-PANI and AuCITRATE NPs presents different morphology as compared to the pure ES-PANI (Figure 3) and Au-CITRATE NPs (Figure 2(a)). The composite particles are larger than ES-PANI and $\mathrm{Au}$-CITRATE NPs, suggesting that the polymer coated the Au-CITRATE NPs. While the exact formation mechanism of such nanostructures is not completely understood, SEM 


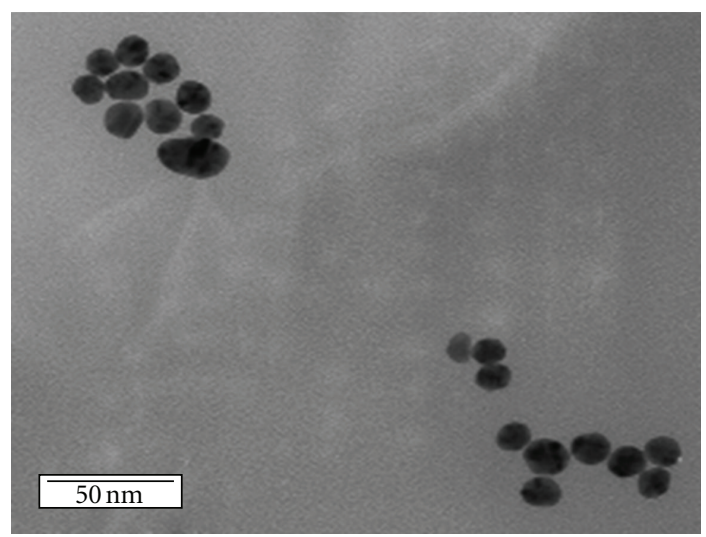

(a)

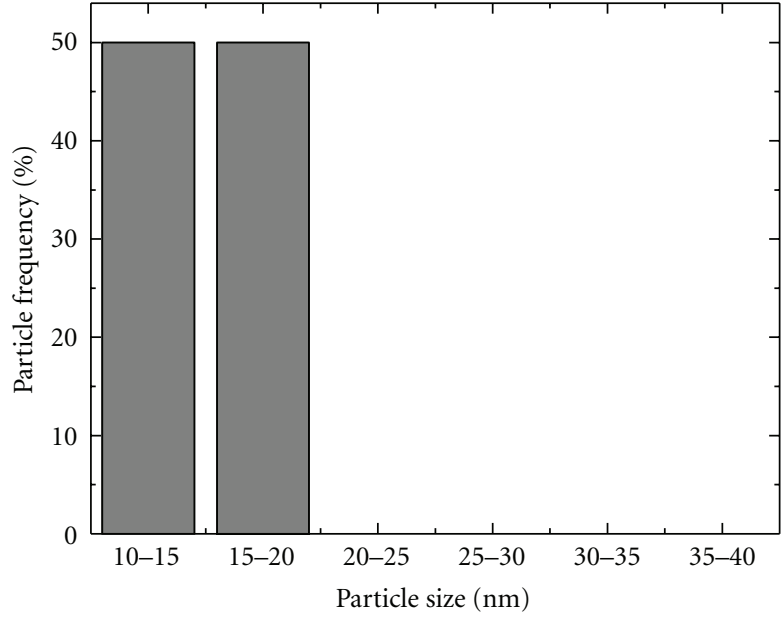

(b)

Figure 2: (a) TEM images of the Au-CITRATE NPs and (b) Histogram of the Au size distribution.

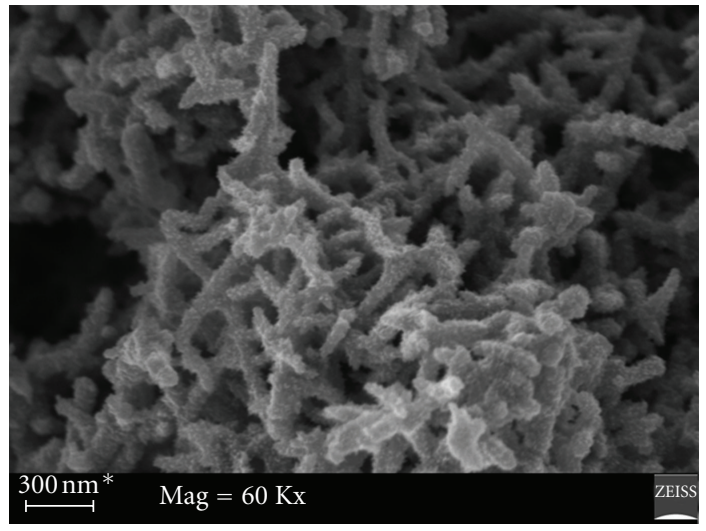

FIgURE 3: SEM images of as-synthesized ES-PANI powder.

images show that the interaction between these materials promotes a formation of new composites.

Crystalline or semicrystalline polymers are two phase systems. The phase in which the polymer chains are ordered in close packed array is the crystalline region. The crystalline domains are connected to the amorphous regions. In the XRD patterns of Au NPs, Pham et al. (2011) found peaks at $38.21^{\circ}, 44.33^{\circ}, 64.58^{\circ}$, and $75.25^{\circ}$, which are assigned to face-centered cubic bulk gold [33]. ES-PANI powder showed broad peaks at $2 \theta=6,9,11,15,20,25,27,29,33,36$, and $52^{\circ}$, which indicate some degree of crystallinity (Figure 6(a)). When the Au-PAMAM NPs were added to the ES-PANI solution, the diffractogram did not present any variation regarding the crystallinity of the polymer semicrystalline phase (Figure 6(b)). XRD pattern of the complex containing ES-PANI and Au-CITRATE NPS is shown in Figure 6(c). It was observed that the addition of Au-CITRATE NPs changed the ES-PANI structure, making it more amorphous after the interaction. ES-PANI showed two broad peaks centered at $2 \theta=11.9$ and $23.4^{\circ}$, which also are characteristic of the polyaniline [34]. Additional peaks at approximately $2 \theta=38$, 44 , and $65^{\circ}$ represent, respectively, Bragg's reflections from

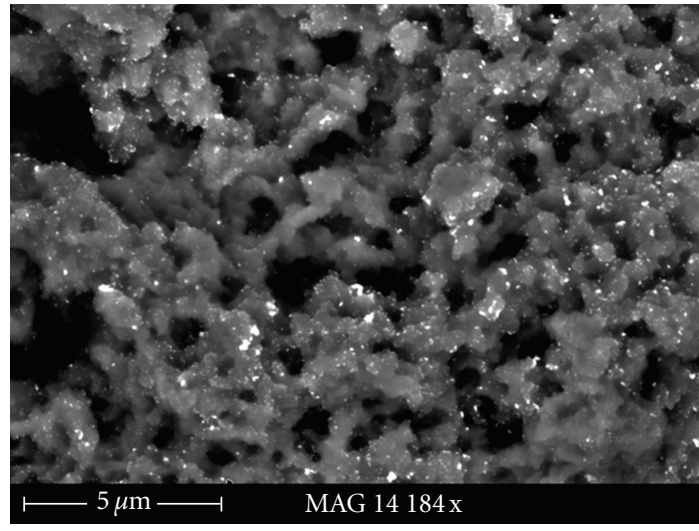

FIGURE 4: SEM images of the Au-PAMAM NPs dispersed on the ESPANI chains.

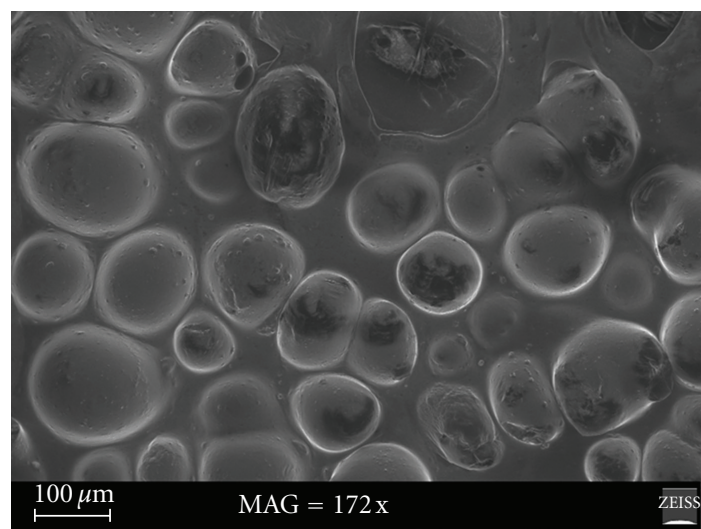

FIGURE 5: SEM images of the complex formed by the interaction between ES-PANI and Au-CITRATE NPs.

Au NPs [33] observed in addition to the peaks of ES-PANI. A suggested formation of the complexes is depicted in Figure 7.

The Zeta potentials are depicted in Table 1 . This measurement indicates the surface potential of the particles and 


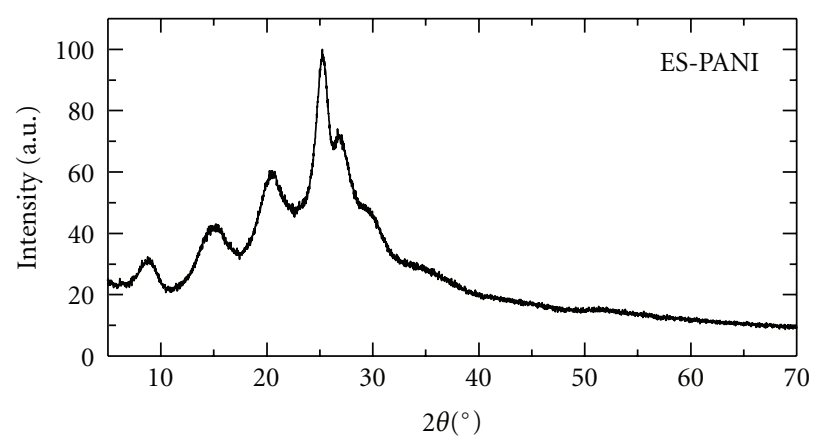

(a)

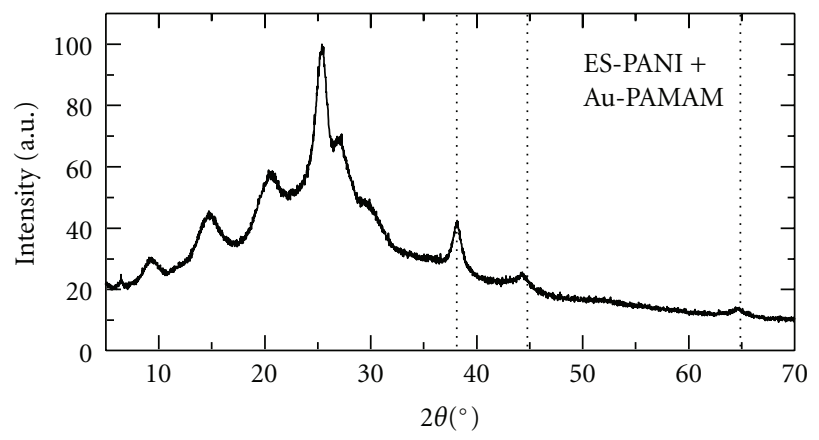

(b)

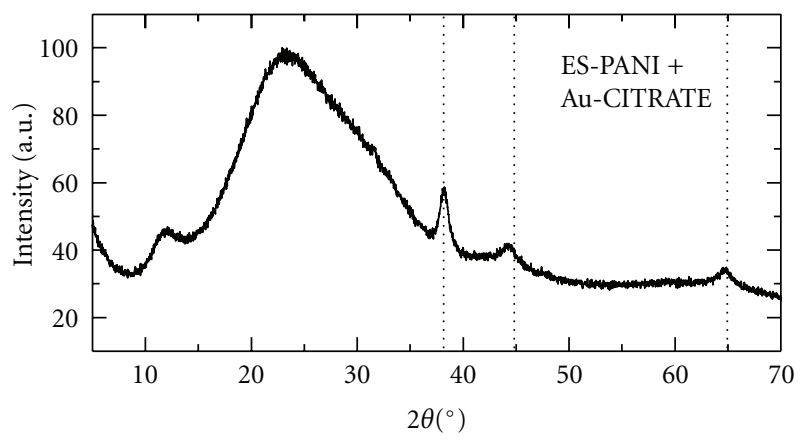

(c)

FIgURE 6: XRD patterns of (a) pure ES-PANI, (b) ES-PANI + Au-PAMAM NPs, and (c) complex containing ES-PANI + Au-CITRATE NPs.

Au-CITRATE NPs

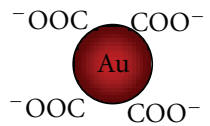

ES-PANI/Au-CITRATE complex

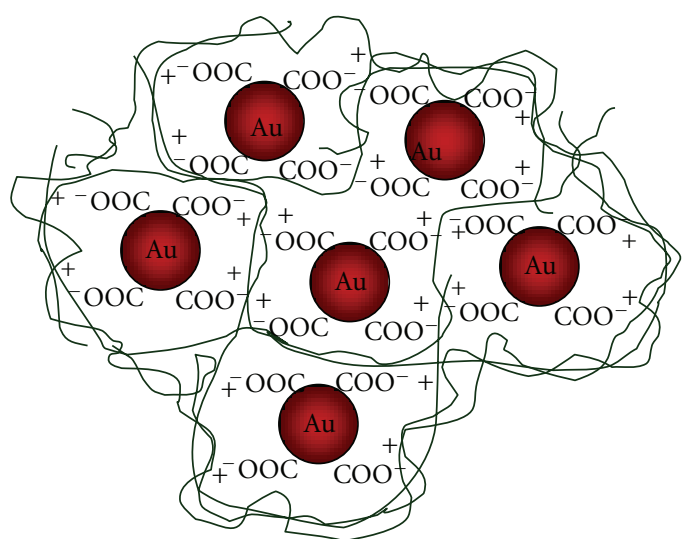

FIGURE 7: Representative structure of the complexes formation between the polymer chains and the Au-CITRATE NPs.

was analyzed as a function of nanoparticles concentration. ES-PANI and Au-PAMAM show positive Zeta potential and Au-CITRATE shows negative zeta potential. After addition of Au-PAMAM to ES-PANI solution, there was observed an increase of the Zeta potential, suggesting no interactions due to the electrostatic repulsion. On the other hand, after adding $50 \mu \mathrm{L}$ of Au-CITRATE to ES-PANI solution, the Zeta potential decreased from 42.0 to $32.2 \mathrm{mV}$, and after adding $500 \mu \mathrm{L}$, the values decreased to $11.4 \mathrm{mV}$, suggesting that the ES-PANI can form a coating on the surface of the AuCITRATE NPs due to the attractive electrostatic interaction between the opposite charges.
Figure 8 shows the FTIR spectra of ES-PANI, AuCITRATE, and ES-PANI with 50, 100, and $500 \mu \mathrm{L}$ of AuCITRATE and the formed complex. The vibrational bands observed for the ES-PANI at 1583 and $1493 \mathrm{~cm}^{-1}$ are assignable to the ring stretching vibration of quinoid and benzenoid, respectively $[35,36]$. A $1299 \mathrm{~cm}^{-1}$ band was assignable to the $\mathrm{C}-\mathrm{N}$ stretching of a secondary aromatic amine [37] and a $825 \mathrm{~cm}^{-1}$ band to an aromatic C-H outof-plane-bending [38]. The $1130 \mathrm{~cm}^{-1}$ band is a vibrational mode of $\mathrm{B}-\mathrm{NH}^{+}=\mathrm{Q}$ or $\mathrm{B}-\mathrm{NH}^{+}-\mathrm{B}$, which is formed in doping reactions [39]. When the concentration of Au-CITRATE was increased, there was noted the appearance of bands located at 
TABLE 1: Zeta Potential of ES-PANI solution as a function of volume of Au-PAMAM and Au-CITRATE NPs.

\begin{tabular}{lc}
\hline Samples & Zeta Potential $(\mathrm{mV})$ \\
\hline ES-PANI & 42.0 \\
Au-PAMAM NPs & 4.0 \\
ES-PANI $+50 \mu \mathrm{L}$ Au-PAMAM & 48.9 \\
ES-PANI + $100 \mu \mathrm{L}$ Au-PAMAM & 57.7 \\
ES-PANI $+500 \mu \mathrm{L}$ Au-PAMAM & 75.5 \\
Au-CITRATE NPs & -31.7 \\
ES-PANI $+50 \mu \mathrm{L}$ Au-CITRATE & 32.2 \\
ES-PANI $+100 \mu \mathrm{L}$ Au-CITRATE & 27.8 \\
ES-PANI $+500 \mu \mathrm{L}$ Au-CITRATE & 11.4 \\
\hline
\end{tabular}

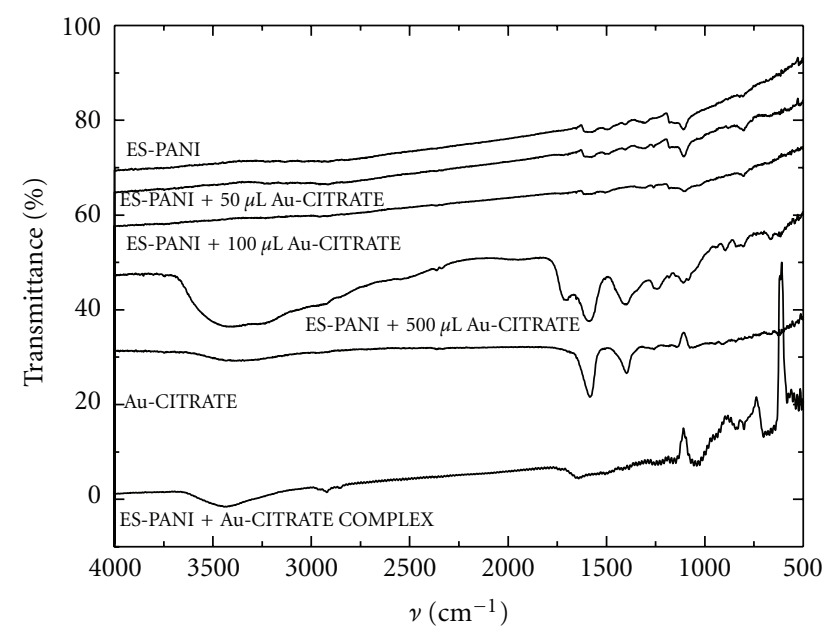

Figure 8: FTIR spectra of ES-PANI, Au-CITRATE, and ES-PANI with 50,100 , and $500 \mu \mathrm{L}$ of Au-CITRATE and the formed complex.

1401 and $1584 \mathrm{~cm}^{-1}$ related, respectively, to the symmetric and antisimmetric stretching of $\mathrm{COO}^{-}$, which were not so clearly alike in pure Au-CITRATE [40]. With respect to the curve of the precipitate, it shows that there were interactions between the ES-PANI and Au-CITRATE NPs, suggesting that the formed material is a complex. These results suggest that $\mathrm{C}-\mathrm{N}$ bonds within the polymer are directly influenced by the Au NPs, which are consistent with the donation of electron density from the metal to the $\mathrm{C}-\mathrm{N}$ bond that are strongly perturbed by the presence of the Au NPs [41, 42].

Similarly, Figure 9 shows the FTIR spectra for ES-PANI, Au-PAMAM, and ES-PANI with 50,100 , and $500 \mu \mathrm{L}$ of Au-PAMAM. When the concentration of Au-PAMAM was increased, there was observed the appearance of bands located at $3275 \mathrm{~cm}^{-1}$ and $3072 \mathrm{~cm}^{-1}$ related to the presence of terminal primary amino groups [43]. The bands located at 2819 and $2945 \mathrm{~cm}^{-1}$ are related, respectively, to the symmetric and antisimmetric vibrations of $\mathrm{CH}_{2}$. The peaks at 1647 and $1562 \mathrm{~cm}^{-1}$ are assigned to the stretching vibration of amide I mainly $\mathrm{C}=\mathrm{O}$ stretching vibrations and amide II due to the coupling of bending vibrate of $\mathrm{N}-\mathrm{H}$ and stretching vibrate of C-N bands, respectively [44]. The spectra showed no structural change when different concentrations of $\mathrm{Au}-$ PAMAM are present in ES-PANI; so there was no precipitate.

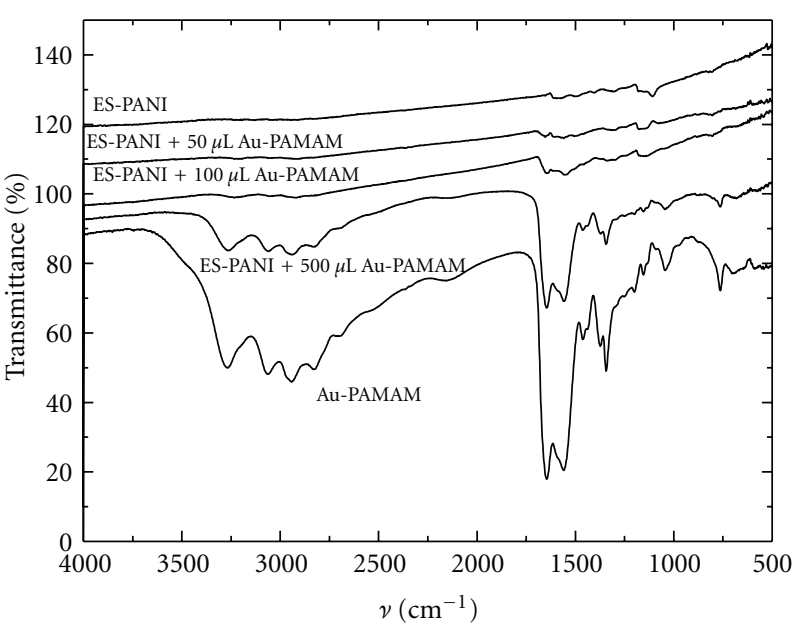

Figure 9: FTIR Spectra for ES-PANI, Au-PAMAM, and ES-PANI with 50,100 , and $500 \mu \mathrm{L}$ of Au-PAMAM.

\section{Conclusions}

We investigated the formation of hybrid composites containing polyaniline and Au NPs. As revealed by the decrease in zeta potential of the ES-PANI/Au-CITRATE, the polyaniline molecules were able to coat the Au-CITRATE NPs, due to the attractive electrostatic interaction between the opposite charges. The same argument applied to ES-PANI/AuPAMAM indicates that the repulsive electrostatic interaction should avoid the formation of complexes. According to these results the interactions between ES-PANI and Au-CITRATE led to differences in their morphologies observed by SEM as well as the XRD pattern of the precipitate containing ES-PANI and Au-CITRATE NPs. The Au-CITRATE caused a structural change on ES-PANI chains, making them less crystalline, but did not affect the crystallinity of ESPANI/Au-PAMAM.

\section{Acknowledgments}

The authors are grateful to the Brazilian Agencies CAPES, FAPESP, and CNPq for their financial support to this work.

\section{References}

[1] R. J. Waltman and J. Bargon, "Electrically conducting polymers: a review of the electropolymerization reaction, of the effects of chemical structure on polymer film properties, and of applications towards technology," Canadian Journal of Chemistry, vol. 64, no. 1, pp. 76-95, 1986.

[2] V. E. Gul, Structure and Properties of Conducting Polymer Composites, VSP, Utrecht, The Netherlands, 1996.

[3] A. N. Shipway and I. Willner, "Nanoparticles as structural and functional units in surface-confined architectures," Chemical Communications, no. 20, pp. 2035-2045, 2001.

[4] T. Ahuja, I. A. Mir, D. Kumar, and Rajesh, "Biomolecular immobilization on conducting polymers for biosensing applications," Biomaterials, vol. 28, no. 5, pp. 791-805, 2007.

[5] M. Jaiswal and R. Menon, "Polymer electronic materials: a review of charge transport," Polymer International, vol. 55, no. 12, pp. 1371-1384, 2006. 
[6] G. M. do Nascimento, P. Y. G. Kobata, R. P. Millen, and M. L. A. Temperini, "Raman dispersion in polyaniline base forms," Synthetic Metals, vol. 157, no. 6-7, pp. 247-251, 2007.

[7] A. G. MacDiarmid, "'Synthetic metals": a novel role for organic polymers (Nobel lecture)," Angewandte Chemie International Edition, vol. 40, no. 14, pp. 2581-2590, 2001.

[8] R. Faez, C. Reis, P. S. Freitas, O. K. Kosima, G. Ruggeri, and M. A. De Paoli, "Polímeros condutores," Quimica Nova na Escola, vol. 11, no. 1, pp. 13-18, 2000.

[9] A. P. Alivisatos, "Semiconductor clusters, nanocrystals, and quantum dots," Science, vol. 271, no. 5251, pp. 933-937, 1996.

[10] J. W. G. Wildöer, L. C. Venema, A. G. Rinzler, R. E. Smalley, and C. Dekker, "Electronic structure of atomically resolved carbon nanotubes,” Nature, vol. 391, no. 6662, pp. 59-62, 1998.

[11] M. Hosseini and M. M. Momeni, "Silver nanoparticles dispersed in polyaniline matrixes coated on titanium substrate as a novel electrode for electro-oxidation of hydrazine," Journal of Materials Science, vol. 45, no. 12, pp. 3304-3310, 2010.

[12] N. V. Blinova, P. Bober, J. Hromádková, M. Trchová, J. Stejskala, and J. Prokeš, "Polyaniline-silver composites prepared by the oxidation of aniline with silver nitrate in acetic acid solutions," Polymer International, vol. 59, no. 4, pp. 437-446, 2010.

[13] G. M. Neelgund, E. Hrehorova, M. Joyce, and V. Bliznyuk, "Synthesis and characterization of polyaniline derivative and silver nanoparticle composites," Polymer International, vol. 57, no. 10, pp. 1083-1089, 2008.

[14] Q. Chang, K. Zhao, X. Chen, M. Li, and J. Liu, "Preparation of gold/polyaniline/multiwall carbon nanotube nanocomposites and application in ammonia gas detection," Journal of Materials Science, vol. 43, no. 17, pp. 5861-5866, 2008.

[15] R. Gangopadhyay and A. De, "Conducting polymer nanocomposites: a brief overview," Chemistry of Materials, vol. 12, no. 3, pp. 608-622, 2000.

[16] G. Schmid and G. L. Hornyak, "Metal clusters-new perspectives in future nanoelectronics," Current Opinion in Solid State and Materials Science, vol. 2, no. 2, pp. 204-212, 1997.

[17] J. Janata and M. Josowicz, "Conducting polymers in electronic chemical sensors," Nature Materials, vol. 2, no. 1, pp. 19-24, 2003.

[18] K. Domanský, J. Li, and J. Janata, "Selective doping of chemically sensitive layers on a multisensing chip," Journal of the Electrochemical Society, vol. 144, no. 4, pp. L75-L78, 1997.

[19] J. H. Kim, J. H. Cho, G. S. Cha, C. W. Lee, H. B. Kim, and S. H. Paek, "Conductimetric membrane strip immunosensor with polyaniline-bound gold colloids as signal generator," Biosensors and Bioelectronics, vol. 14, no. 12, pp. 907-915, 2000.

[20] D. D. Borole, U. R. Kapadi, P. P. Mahulikar, and D. G. Hundiwale, "Glucose oxidase electrodes of polyaniline, poly(oanisidine) and their co-polymer as a biosensor: a comparative study," Journal of Materials Science, vol. 42, no. 13, pp. $4947-$ 4953, 2007.

[21] X. H. Xu, G. L. Ren, J. Cheng, Q. Liu, D. G. Li, and Q. Chen, "Self-assembly of polyaniline-grafted chitosan/glucose oxidase nanolayered films for electrochemical biosensor applications," Journal of Materials Science, vol. 41, no. 15, pp. 4974-4977, 2006.

[22] D. C. Trivedi, "Polyanilines," in Handbook of Organic Conductive Molecules and Polymers: Synthesis and Electrical Properties, Conductive Polymers: Synthesis and Electrical Properties, H. S. Nalwa, Ed., vol. 2, p. 550, John Wiley \& Sons, New York, NY, USA, 1997.
[23] D. J. Strike, N. F. De Rooij, M. Koudelka-Hep, M. Ulmann, and J. Augustynski, "Electrocatalytic oxidation of methanol on platinum microparticles in polypyrrole," Journal of Applied Electrochemistry, vol. 22, no. 10, pp. 922-926, 1992.

[24] J. R. Siqueira, F. N. Crespilho, V. Zucolotto, and O. N. Oliveira, "Bifunctional electroactive nanostructured membranes," Electrochemistry Communications, vol. 9, no. 11, pp. 2676-2680, 2007.

[25] Y. Ma, N. Li, C. Yang, and X. Yang, “One-step synthesis of water-soluble gold nanoparticles/polyaniline composite and its application in glucose sensing," Colloids and Surfaces A, vol. 269, no. 1-3, pp. 1-6, 2005.

[26] M. Antonietti, S. Förster, J. Hartmann, and S. Oestreich, "Novel amphiphilic block copolymers by polymer reactions and their use for solubilization of metal salts and metal colloids," Macromolecules, vol. 29, no. 11, pp. 3800-3806, 1996.

[27] Y. C. Liu and L. Y. Jang, "Relationship between crystalline orientations of gold and surface-enhanced Raman scattering spectroscopy of polypyrrole and mechanism of roughening procedure on gold via cyclic voltammetry," Journal of Physical Chemistry B, vol. 106, no. 26, pp. 6748-6753, 2002.

[28] S. Tian, J. Liu, T. Zhu, and W. Knoll, "Polyaniline/gold nanoparticle multilayer films: assembly, properties, and biological applications," Chemistry of Materials, vol. 16, no. 21, pp. 41034108, 2004.

[29] X. Feng, G. Yang, Q. Xu, W. Hou, and J. J. Zhu, "Self-assembly of polyaniline/Au composites: from nanotubes to nanofibers," Macromolecular Rapid Communications, vol. 27, no. 1, pp. 3136, 2006.

[30] F. N. Crespilho, M. Emilia Ghica, M. Florescu, F. C. Nart, O. N. Oliveira, and C. M. A. Brett, "A strategy for enzyme immobilization on layer-by-layer dendrimer-gold nanoparticle electrocatalytic membrane incorporating redox mediator," Electrochemistry Communications, vol. 8, no. 10, pp. 1665-1670, 2006.

[31] N. Pernodet, X. Fang, Y. Sun et al., "Adverse effects of citrate/ gold nanoparticles on human dermal fibroblasts," Small, vol. 2, no. 6, pp. 766-773, 2006.

[32] S. Bhadra, N. K. Singha, and D. Khastgir, "Electrochemical synthesis of polyaniline and its comparison with chemically synthesized polyaniline," Journal of Applied Polymer Science, vol. 104, no. 3, pp. 1900-1904, 2007.

[33] T. A. Pham, B. C. Choi, K. T. Lim, and Y. T. Jeong, "A simple approach for immobilization of gold nanoparticles on graphene oxide sheets by covalent bonding," Applied Surface Science, vol. 257, no. 8, pp. 3350-3357, 2011.

[34] J. P. Pouget, M. E. Józefowicz, A. J. Epstein, X. Tang, and A. G. MacDiarmid, "X-ray structure of polyaniline," Macromolecules, vol. 24, no. 3, pp. 779-789, 1991.

[35] C. A. Amarnath and S. Palaniappan, "Polyaniline doped by a new class of dopants, benzoic acid and substituted benzoic acid: synthesis and chracterization," Polymers for Advanced Technologies, vol. 16, no. 5, pp. 420-424, 2005.

[36] M. S. Cho, S. Y. Park, J. Y. Hwang, and H. J. Choi, "Synthesis and electrical properties of polymer composites with polyaniline nanoparticles," Materials Science and Engineering C, vol. 24, no. 1-2, pp. 15-18, 2004.

[37] J. Tang, X. Jing, B. Wang, and F. Wang, "Infrared spectra of soluble polyaniline," Synthetic Metals, vol. 24, no. 3, pp. 231238, 1988.

[38] X. R. Zeng and T. M. Ko, "Structures and properties of chemically reduced polyanilines," Polymer, vol. 39, no. 5, pp. 11871195, 1998. 
[39] D. W. Hatchett, M. Josowicz, and J. Janata, "Acid doping of poly aniline: spectroscopic and electrochemical studies," Journal of Physical Chemistry B, vol. 103, no. 50, pp. 10992 10998, 1999.

[40] X. Zou, E. Ying, and S. Dong, "Seed-mediated synthesis of branched gold nanoparticles with the assistance of citrate and their surface-enhanced Raman scattering properties," Nanotechnology, vol. 17, no. 18, article no. 038, pp. 4758-4764, 2006.

[41] J. M. Kinyanjui, J. Hanks, D. W. Hatchett, A. Smith, and M. Josowicz, "Chemical and electrochemical synthesis of polyaniline/gold composites," Journal of the Electrochemical Society, vol. 151, no. 12, pp. D113-D120, 2004.

[42] J. M. Kinyanjui, D. W. Hatchett, J. A. Smith, and M. Josowicz, "Chemical synthesis of a polyaniline/gold composite using tetrachloroaurate," Chemistry of Materials, vol. 16, no. 17, pp. 3390-3398, 2004.

[43] A. Asthana, A. S. Chauhan, P. V. Diwan, and N. K. Jain, "Poly(amidoamine) (PAMAM) dendritic nanostructures for controlled site-specific delivery of acidic anti-inflammatory active ingredient," American Association of Pharmaceutical Scientists, vol. 6, no. 3, pp. E536-542, 2005.

[44] P. Huang, Z. Li, J. Lin, and D. Cui, "Preparation of surface dendrimer-modified gold nanorods by round-trip phase transfer ligand exchange," Journal of Physics: Conference Series, vol. 188, Article ID 012031, 2009. 

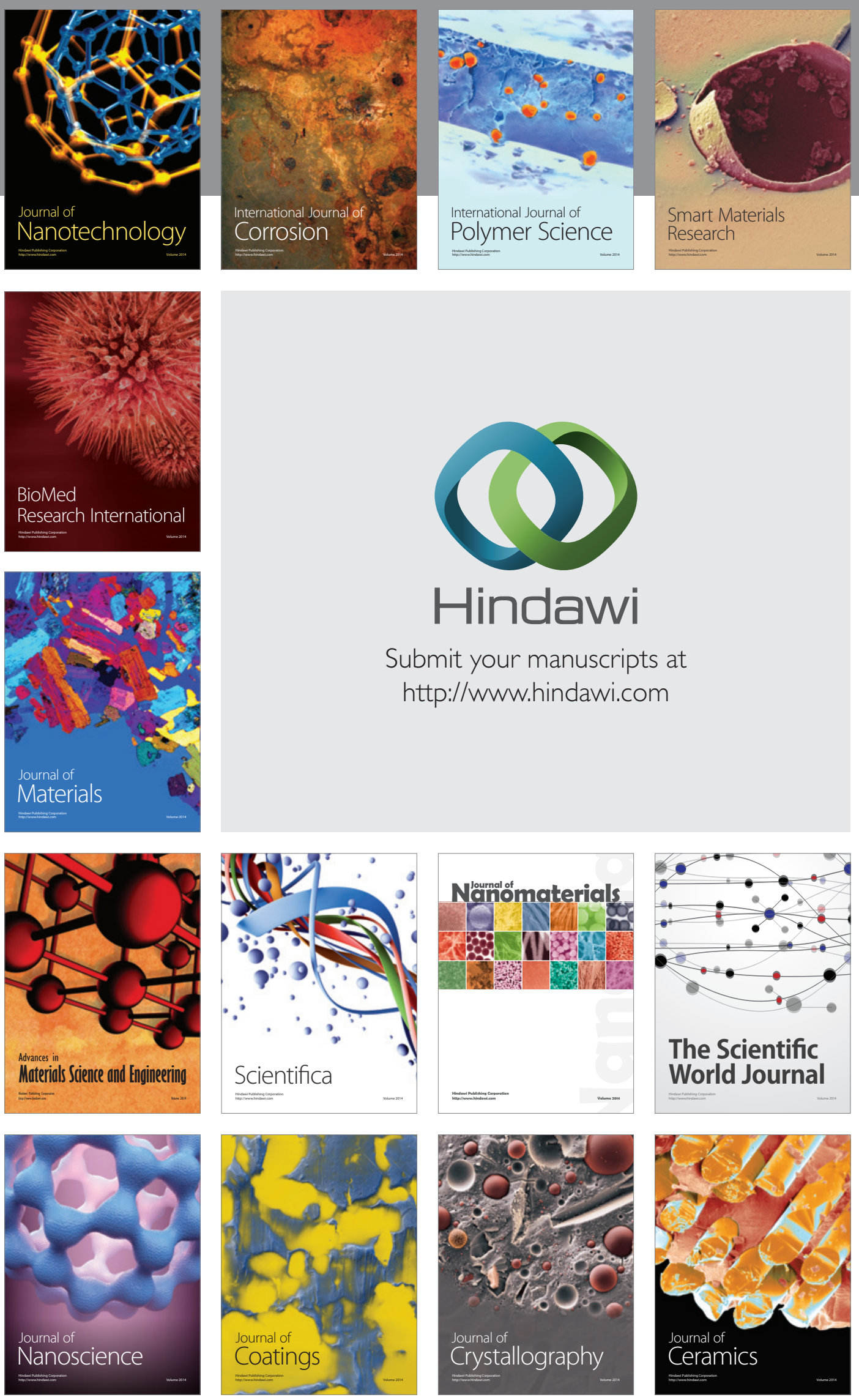

The Scientific World Journal

Submit your manuscripts at

http://www.hindawi.com

\section{World Journal}

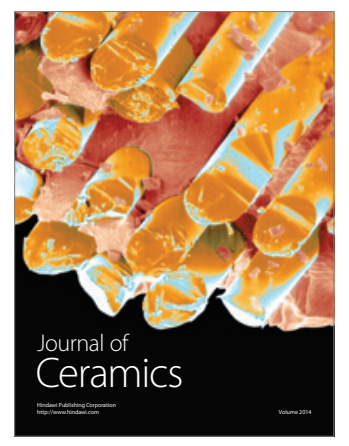

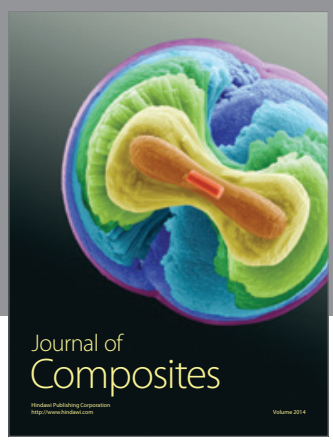
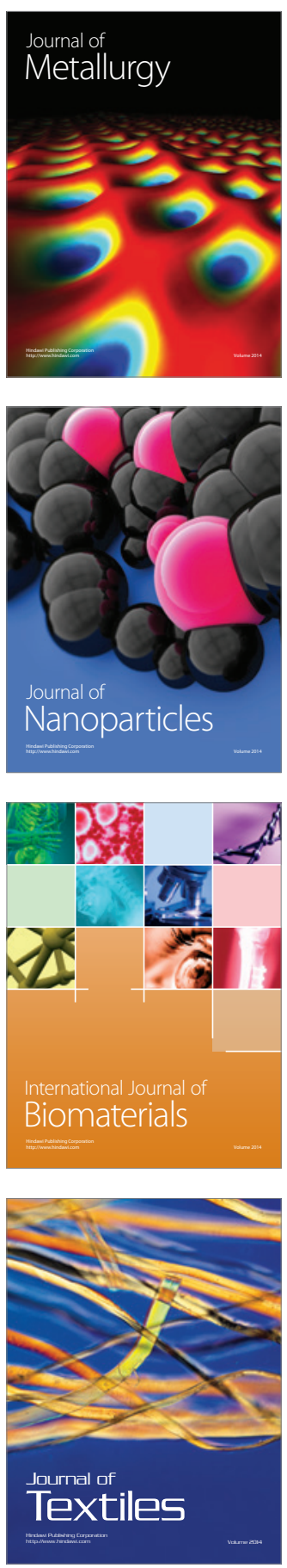